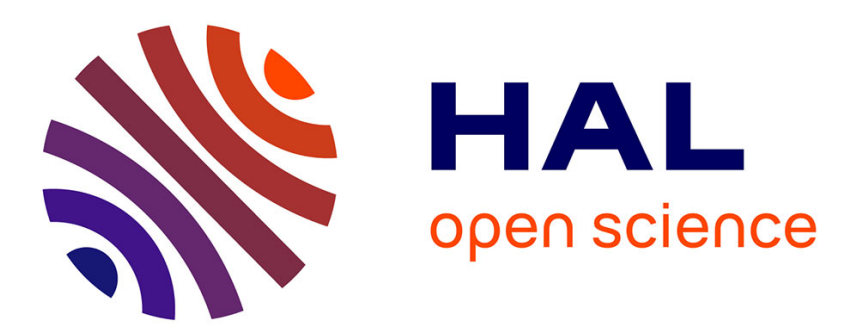

\title{
Assimilation of soil moisture inferred from infrared remote sensing in a hydrological model over the HAPEX-MOBILHY region
}

\author{
C Ottle, Daniel Vidal-Madjar
}

\section{- To cite this version:}

C Ottle, Daniel Vidal-Madjar. Assimilation of soil moisture inferred from infrared remote sensing in a hydrological model over the HAPEX-MOBILHY region. Journal of Hydrology: Regional Studies, 1994, 158, pp.241-264. hal-03299116

\section{HAL Id: hal-03299116 https://hal.science/hal-03299116}

Submitted on 26 Jul 2021

HAL is a multi-disciplinary open access archive for the deposit and dissemination of scientific research documents, whether they are published or not. The documents may come from teaching and research institutions in France or abroad, or from public or private research centers.
L'archive ouverte pluridisciplinaire HAL, est destinée au dépôt et à la diffusion de documents scientifiques de niveau recherche, publiés ou non, émanant des établissements d'enseignement et de recherche français ou étrangers, des laboratoires publics ou privés. 


\title{
Assimilation of soil moisture inferred from infrared remote sensing in a hydrological model over the HAPEX-MOBILHY region
}

\author{
C. Ottlé*, D. Vidal-Madjar \\ CRPE, Centre Universitaire, 10-12 Av. de l'Europe, 78140 Velizy, France
}

(Received 3 June 1993; revision accepted 16 January 1994)

\begin{abstract}
Hydrological models are generally unable to simulate correctly water exchanges at the soilatmosphere interface and the time evolution of surface soil humidity. This drawback often leads to poor simulation of water flows after periods of low flows because of the wrong estimation of the surface soil water content. In this paper, we describe how remote sensing can be used to account for the vegetation in the estimation of the actual evapotranspiration, and to estimate soil moisture regularly throughout the year and use it to correct the model simulation. This work has been done on the Adour river basin, in the framework of the HAPEX-MOBILHY experiment. The results presented show the improvements that result from the use of remote sensing data in hydrological modelling: better simulation of the soil moisture and of water flows at the outlets, and more realistic calculation of evaporation.
\end{abstract}

\section{Introduction}

The understanding of the continental water cycle and of the parameters that characterize the hydrological environment requires the modelling of the hydrological systems to control the surface and the underground water. If one wants to describe the hydrological processes and to take into account the physical relations between the causes and the effects, deterministic models have to be used. Such modelling is not staightforward. Difficulties generally arise from the lack of information on several factors. The first and most important one is the variation of precipitation and evaporation with time and space; other factors are the spatial variations of watershed characteristics (topography, soils, vegetation, etc.), the anthropogenic influences on

\footnotetext{
*Corresponding author. 
the components of the hydrological cycle, and the non-linearity of the mass and energy transfer processes.

Because of their high variability in space and time, precipitation and evaporation are generally not known accurately, and originate from a few meteorological stations located across the watershed, which are not able to provide data at the model grid resolution. For this reason, remote sensing is the only way to provide more information on these variables because it gives integrated parameters on the pixel scale.

Recent studies have shown that precipitation, evaporation, snow cover height, land uses, soil types and soil moisture are parameters which can be estimated from space with visible, IR or microwave sensors (Kustas et al., 1989).

In this study, we show how satellite remote sensing can be used to improve the calculation of the surface hydrological budget simulated by a hydrological model over a large watershed. We show how visible and near-IR data can be used to predetermine land surface parameters, and how thermal IR data are suitable to estimate the surface energy budget and consequently the evaporation.

Various studies have shown that the surface temperature estimated from space can be used to infer surface fluxes such as evaporation and soil moisture by using a rough surface model, provided the measurements are made around the maximum daily value (Carlson et al., 1981; Taconet et al., 1986). As evaporation is a parameter that varies with time, and as this method only applies when cloudless satellite images are available over the region under study, it cannot be assimilated directly in the hydrological model. It is preferable to estimate the soil humidity in the soil layer contributing to the evapotranspiration. This parameter is less variable with time and can be used to provide regular corrections of the surface reservoir content simulated by the hydrological model.

We have chosen to work with NOAA-AVHRR (advanced very high resolution radiometer) satellite data because of the overpass time of this satellite over the region (around 13:00 h) and its repetitivity. Our method is illustrated in Fig. 1. From knowledge of precipitation and potential evaporation, the hydrological model simulates the evolution of the soil moisture $\left(W_{\mathrm{p}}\right)$ in the surface layer of the watershed and the waterflows on a daily time basis. At the same time, when a clear sky satellite image is available (for day $j=j_{\mathrm{s}}$ ), the interface model can be run provided the atmospheric forcing and the soil and vegetation parameters are known. Then, the surface temperature estimated from the satellite IR data permits us to estimate the surface soil humidity over the river basin which can be finally assimilated in the hydrological model for this particular day. The hydrological simulation, corrected in this way, is continued until another cloudless image is available.

This work has been done in the framework of the HAPEX-MOBILHY (hydrologic atmospheric experiment-modilisation du bilan hydrique) experiment with the hydrological model of Girard (1974) and Ledoux (1980), which is a distributed conceptual model implemented over the Adour river basin in SW France.

First, the general method is presented. Then, after a brief description of the experiment and of the hydrological model used, we show how to obtain soil moisture from IR data, and describe its assimilation in the hydrological model and the results obtained. 


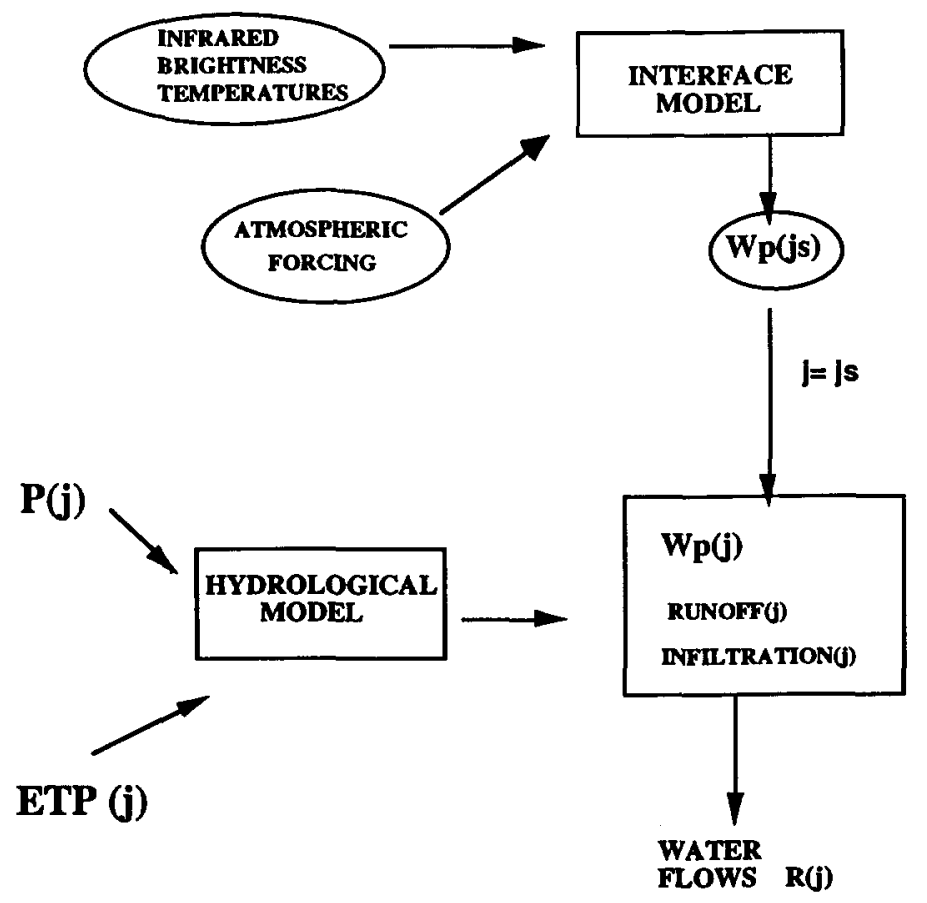

Fig. 1. Presentation of the method.

\section{The HAPEX-MOBILHY experiment: general description}

The HAPEX-MOBILHY programme (hereafter HM), has been initiated to study the hydrological budget and the evaporation fluxes at the scale of a general circulation model grid square of the order of $100 \mathrm{~km} \times 100 \mathrm{~km}$ (André et al., 1988).

This experiment took place in France during a period of 2 years in 1985-1986. The chosen site is situated in the SW of the country and watered by the Adour river system, as shown in Fig. 2. The upper part of the region is covered by the Landes forest and the rest of the grid square by mixed crops. Although this experiment has been described in many papers, it may be useful to recall here the major pieces of equipment which have been installed within the region: 42 Prévision Améliorée, Technique d'Affinement de la Climatologie (PATAC) automatic weather stations (Service Météorologique Inter Régional Sud-Ouest (SMIRSO), 1985), 59 rain gauges, 33 streamflow gauges, 12 Système Automatique de Mesure de l'Evapotranspiration Réelle stations devoted to the measurements of the various components of the surface energy budget (Itier, 1982; Riou, 1982) and equipped with neutron probes for soil moisture profile measurements.

During a special observing period (SOP), between 7 May 1986 and 15 July 1986, additional measurements were performed: intensive tropospheric radiosoundings, airborne fluxes and radiometric measurements with NCAR King-Air and NASA C130 aircraft, and simultaneously, ground-truth measurements relating to 


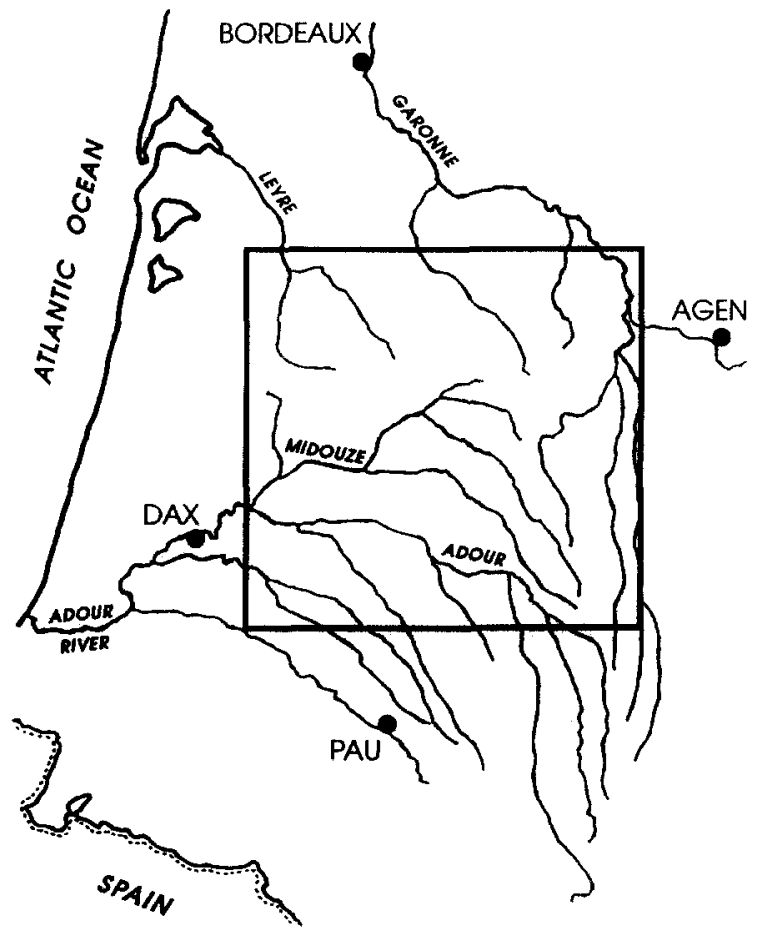

Fig. 2. The Adour river system.

vegetation processes. Concerning satellite data, all the cloudless NOAA-AVHRR images available at the Space Meteorological Centre (CMS) in Lannion (France) have been archived as well as a LANDSAT Thematic Mapper (TM) image of the HAPEX square. To simulate the streamflows over the Adour river basin, a hydrological model (Girard and Boukerma, 1985) has been implemented.

\section{The hydrological model}

\subsection{Model description}

The model has already been described by Ottle and Vidal-Madjar (1989). It is a deterministic model, composed of two coupled domains, the surface layer and the underground layer. In the surface layer, the rainfall is subdivided into storage, runoff and infiltration. In the underground layer, the model calculates the transfer to and between the water tables. As more than $90 \%$ of the ground water transfers take place in the first aquifer, the underground domain is represented by only one layer. The two domains (the surface and underground layers) have been discretized over square meshes with sides ranging from $1.25 \mathrm{~km}$ to $5 \mathrm{~km}$. The discretization of the surface layer is composed of 1208 meshes. For each of these meshes, the direction of the water 


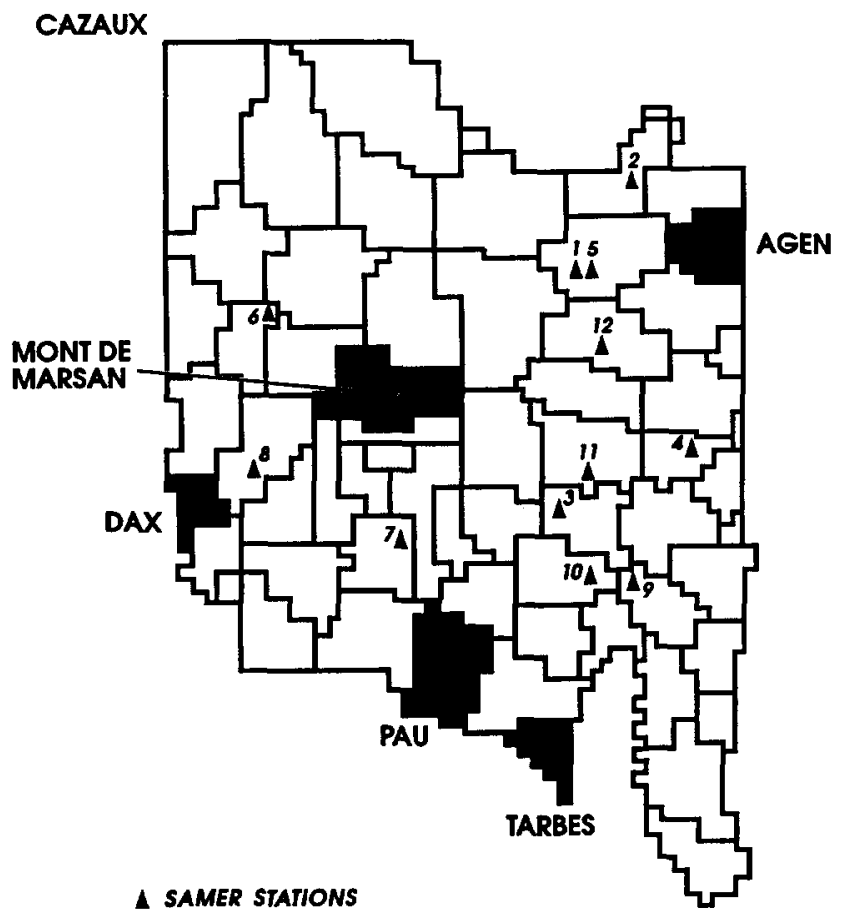

Fig. 3. Map of the meteorological zones.

flows has been plotted based on the topographic analysis, and ten outlets have been kept corresponding to ten watersheds, of which five are under control. An important point for the simulation of the surface runoff is the characterization of the different soil types for each surface mesh. From geological, pedological and survey maps, a soil classification composed of nine classes has been defined and a percentage of each of these soil types has been assigned to each mesh (Ottlé et al., 1989).

The surface domain has been divided in 84 homogeneous precipitation zones grouping meshes for which the same daily amount of rainfall is assigned. Then, these zones have been grouped into six evaporative zones around the meteorological stations where potential evaporation is measured routinely (Fig. 3). These stations are Agen, Mont de Marsan, Pau, Cazaux, Tarbes and Dax.

The model simulates the water flows by means of three mechanisms: the first is the production function which subdivides rainfall into storage within the first reservoir, surface runoff, evaporation and infiltration into the underground layer. The second mechanism calculates the surface transport, routing the runoff from each grid-point to the closest river mesh following the drainage directions (Fig. 4). Finally, the third routine calculates the infiltration into the water tables, the underground transfers and the water flows coming back up to the surface layer, which are allowed only in the river meshes. The time step of the calculations is 1 day. This is sufficient for our 


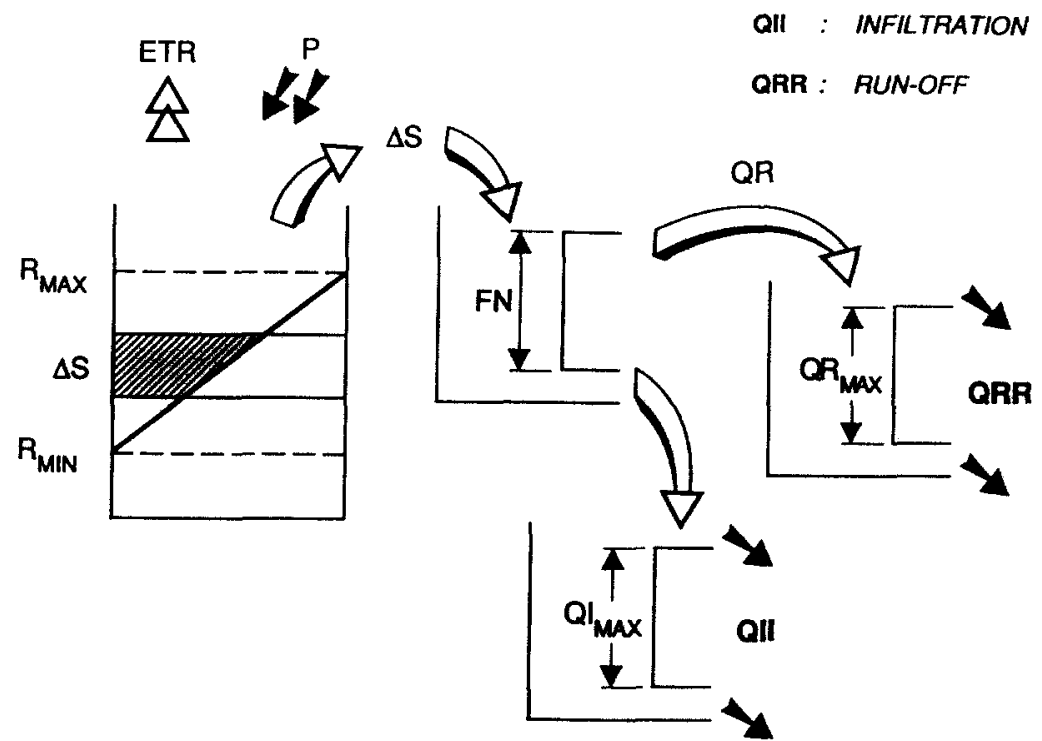

Fig. 4. Production scheme of the hydrological model.

purpose which is to perform simulations over time periods of one decade. The coupled model has been calibrated on a time period of 9 years to set the water capacities, the infiltration rates and the concentration times for each soil type. The model has then been run on the 2 years of the HM experiment.

The primary objective of this work is to improve the simulation of the water budget, especially the estimation of the actual evapotranspiration, and to assimilate soil water contents of soil layers contributing to the evaporation. For this purpose, it has been necessary to separate the surface reservoir into two layers: the superficial soil layer corresponding to the first $10 \mathrm{~cm}$ of soil, and the root zone of the vegetation, extending approximately through the first $1 \mathrm{~m}$. Consequently, we have introduced in the hydrological model the surface parametrization already used in our (surface fluxes/surface temperature) inversion model.

\subsection{Description of the production scheme of the hydrological model}

As presented in our first paper (Ottle et al., 1989), the surface parametrization of the hydrological model (Girard and Boukerma, 1985) has to be changed to allow for the coupling to the interface model. The surface layer is now represented by the surface parametrization derived from Deardorff (1977), and proposed by Bernard et al. (1986). The surface layer is represented as shown in Fig. 5, by two layers (the surface layer is included in the bulk layer) and the soil humidities are calculated by a force restore method.

The time evolution of the soil moistures $W_{\mathrm{s}}$ for the superficial layer and $W_{\mathrm{p}}$ for the bulk layer are given by the following equations:

$$
\frac{\partial W_{\mathrm{s}}}{\partial t}=\frac{P-E_{\mathrm{s}}}{\mathrm{d} s}-C\left(W_{\mathrm{s}}, W_{\mathrm{p}}\right)\left(W_{\mathrm{s}}-W_{\mathrm{p}}\right)
$$


E(t) Evaporation

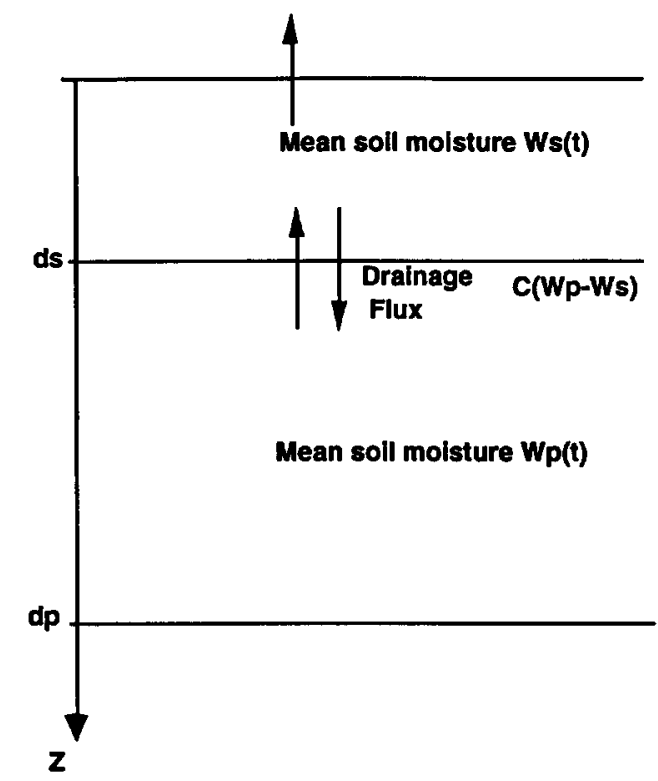

Soil Surface

Fig. 5. Surface parametrization proposed by Bernard et al. (1986).

$$
\frac{\partial W_{\mathrm{p}}}{\partial t}=\frac{P-R-E_{\mathrm{p}}}{\mathrm{d} p}
$$

where $\mathrm{d} s=0.1 \mathrm{~m}$ and $\mathrm{d} p=1.2 \mathrm{~m}$ are the respective heights of the two layers of water content $W_{\mathrm{s}}$ and $W_{\mathrm{p}}, P$ is precipitation, $E_{\mathrm{s}}$ is the surface evaporation, $E_{\mathrm{p}}$ is the bulk layer evaporation, $R$ is the surface runoff (calculated only in the case of bare soil to take into account the fact that rainfall infiltrates better over vegetated areas than over bare soils), and $C$ is a pseudo-diffusivity which is a function of the hydraulic diffusivity and of the thickness of the two layers.

When the bulk layer is saturated, the excess water is subdivided into infiltration to the underground and runoff to the river, depending on the infiltration threshold $F_{\mathrm{n}}$. Finally, if necessary, two additional reservoirs add a delay to the infiltration and to the runoff. To improve the calculation of the evaporation, we have separated the evaporation of the bare soil from the evapotranspiration, according to Deardorff (1978).

\subsection{Modelling evapotranspiration}

The study of the local fluxes measured by the SAMER stations during the experiment allowed us to adjust the parametrization of the evaporation functions in the hydrological model. According to the results of BenMehrez et al. (1992a,b), it appears necessary to take into account the nature of the surface and its vegetation cover and to calculate the total evaporation as the sum of the contributions of the vegetation 
and of the bare surface. For that purpose, it is necessary to determine, throughout the year, the land use classification and the fraction of vegetation cover.

The land use classification has been performed using satellite optical imagery. The spectral properties of leaves and particularly of chlorophyll leads to the vegetation having a low reflectance in the visible range and a high reflectance in the near-IR range. Therefore, a combination of these two reflectances is a good indicator of the vegetation amount. The normal difference vegetation index (NDVI) (Deering et al., 1975) is defined as follows:

$$
\mathrm{NDVI}=\frac{R_{\mathrm{NIR}}-R_{\mathrm{VIS}}}{R_{\mathrm{NIR}}+R_{\mathrm{VIS}}}
$$

where $R$ are reflectances and the indices NIR and VIS refer to the near-IR and visible spectral bands. The vegetation fractional cover $f c$ can be deduced from the study of the yearly variation of this index using the equation

$$
f c=\frac{\mathrm{NDVI}-\mathrm{NDVI}_{\text {min }}}{\mathrm{NDVI}_{\max }-\mathrm{NDVI}_{\min }}
$$

where $\mathrm{NDVI}_{\min }$ and $\mathrm{NDVI}_{\max }$ are the minimum and maximum values observed during the whole vegetative period.

\section{Satellite image processing}

All the NOAA-AVHRR images archived for this project have been processed in our laboratory. The image processing involves calibration and registration. The calibration has been done using the coefficients given by the AVHRR on-board calibration. The images were rectified to geographic coordinates. Registration and resampling eventually lead to an image with $1 \mathrm{~km}^{2}$ pixels. At this stage of the corrections, the images are not all coregistered and there remains a little offset that is corrected through visual exploration on an image-processing workstation. The AVHRR radiometer makes measurements in five spectral bands. The first channel corresponds to visible wavelengths, the second to near-IR, the third to medium IR and the fourth and fifth to thermal IR. To compute the NDVI, we have taken the two first channels of the radiometer.

However, this index depends on the solar and viewing angles and is very sensitive to atmospheric properties and to the presence of aerosols. Therefore, to estimate $f c$, it is necessary to apply corrections to minimize these effects. The data have been corrected using a simplified version of the radiative transfer model 5S (Tanré et al., 1990) developed by Phulpin et al. (1989). Then, we have selected in our data base, containing about 200 images, the maximum NDVI images on a weekly basis: 26 images have been kept in this way. This method permits us to select only the situations of minimum aerosols content (Holben et al., 1986).

The analysis of these images and the comparison with the classification of the vegetation made from a LANDSAT TM image of 16 June (J. Hirsch, personal communication, 1988) combined with ground-truth information allowed us to distinguish four classes in the HM region-forests, winter crops, summer crops and mixed crops regions-whose behaviours are clearly differentiated. In Fig. 6, the 

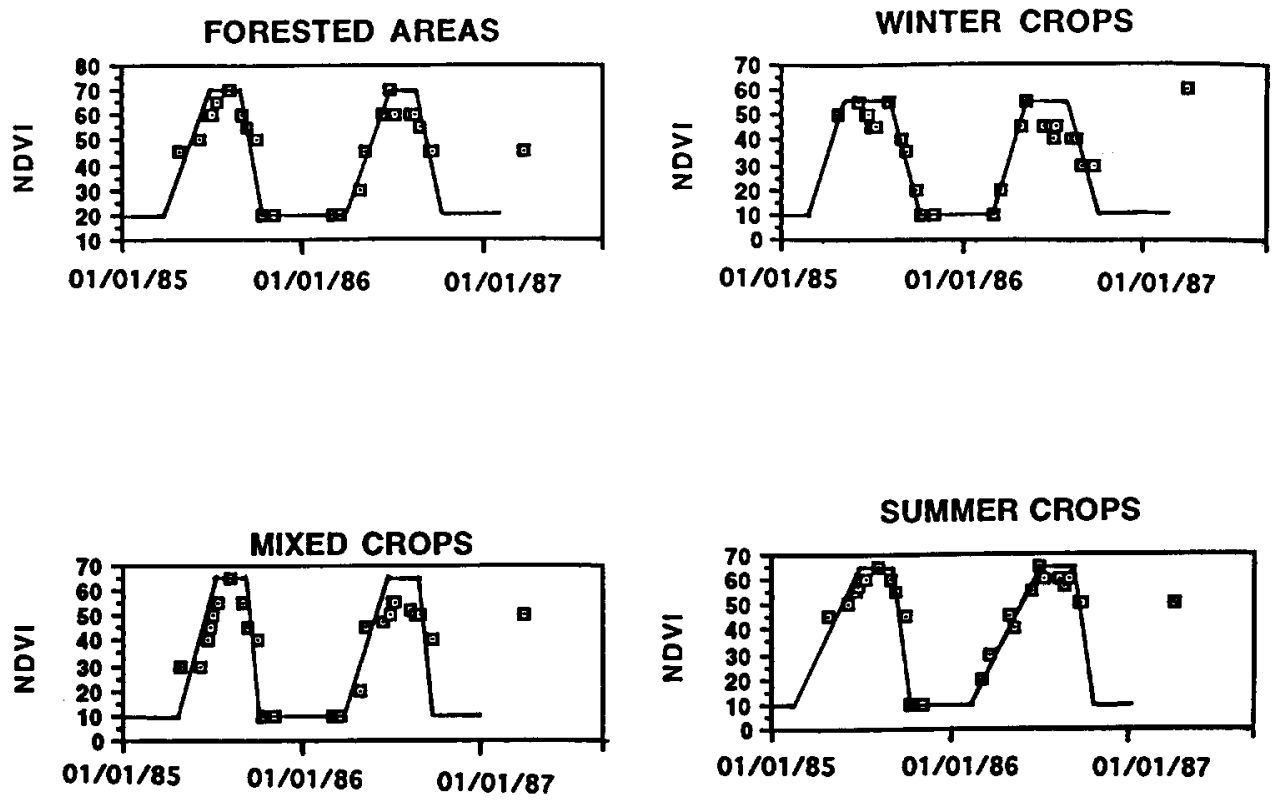

Fig. 6. Temporal variation of the NDVI for the different classes of vegetation.

NDVI for each of these four classes is plotted. It can be seen that the variation of the NDVI is about the same for the 2 years of the experiment. Also, it is possible from these plots to differentiate four periods in the vegetative cycle: the period of bare soil when the NDVI is minimum; the period of vegetation growth when the NDVI rises to its maximum value; the period of maturity characterized by constant values; the senescence period with a rapid decrease of the index. As our purpose is only to determine the beginning of these four periods, the variations of the NDVI can be approximated by segments of straight lines.

\section{Calculation of the evaporation}

For these four periods, the vegetation fractional cover has been deduced and the total evaporation of the bulk layer can be calculated by the following equation:

$$
E_{\mathrm{p}}=f c E_{\mathrm{v}}+(1-f c) E_{\mathrm{bs}}
$$

where $E_{\mathrm{v}}$ is the daily evapotranspiration and $E_{\mathrm{bs}}$ is the daily bare soil evaporation. As the input for the hydrological model is the decade potential evaporation, it appears necessary to parametrize $E_{\mathrm{bs}}$ and $E_{\mathrm{v}}$ in terms of the potential evaporation and of the soil moisture. For the evaluation of $E_{\mathrm{v}}$, we also have to take into account the state of maturity of the vegetation because it strongly influences the stomatal resistance to evapotranspiration. To fit these formulations, the interface model has been run and the flux measurements made at the SAMER stations have been used.

Following the work of BenMehrez et al. (1992a,b), the functional parameters of the interface model have been calibrated for all the soils (sand and sandy loam) and 
Table 1

Coefficients for the calculation of the limit evaporation for the various soil types

\begin{tabular}{llll}
\hline & $a$ & $b$ & $W_{\text {sat }}$ \\
\hline Sand & 30 & 37 & 0.35 \\
Sandy loam & 26 & 49 & 0.42 \\
Loamy clay & 15 & 5 & 0.55 \\
\hline
\end{tabular}

vegetation types (corn and oat crops) available during the SOP of the HM experiment. The results lead to a fitting of the following functions.

(1) Bare soil evaporation $E_{\mathrm{bs}}$ is estimated by

$$
E_{\mathrm{bs}}=\alpha E_{\mathrm{pot}}
$$

where $\alpha$ is a soil resistance coefficient which takes into account the surface drying and $E_{\text {pot }}$ is the potential evaporation. It is based on the concept of limit evaporation (Wetzel and Chang, 1987; Soarès at al., 1988), and is defined by analytic expressions depending on the soil hydraulic diffusivity. $\alpha$ can be written as

$$
\alpha=\min \left(1, E_{\mathrm{lim}} / E_{\mathrm{pot}}\right)
$$

$E_{\text {lim }}$ has been fitted according to the function given by Soarès et al. (1988) for the two soil types (sand and sandy loam):

$$
E_{\lim }=a \exp \left(b W_{\mathrm{s}}^{2}\right) \frac{W_{\text {sat }}}{\left(W_{\text {sat }}-W_{\mathrm{s}}\right)}
$$

where $a$ and $b$ are constants depending on the soil nature and $W_{\text {sat }}$ is the saturation soil moisture. All numerical values of these parameters are given in Table 1. Over the HAPEX square, a few loamy clay soils can also be found. As no SAMER stations were installed on these soils, coefficients $a, b$ and $W_{\text {sat }}$ have been set to the values found in a previous work over a loamy clay soil in Finland (Sucksdorff and Ottlé, 1990).

(2) The evapotranspiration $E_{\mathrm{v}}$ is estimated by

$$
E_{\mathrm{v}}=\beta E_{\mathrm{pot}}
$$

where $\beta$ is a coefficient depending on the root zone moisture and on the daily resistance to evapotranspiration. To adjust these functions, the daily evaporation fluxes measured at the SAMER stations have been fitted for two different periods of maturity of the vegetation: during the growing period and after maturity. The relationships have been fitted by regression on the soil humidity, and the following formulations have been found.

Before maturity:

$$
\beta=1-\exp \left(-7 W_{\mathrm{p}} / W_{\text {sat }}\right)
$$

After maturity:

$$
\beta=0.25\left[1-\exp \left(-5 W_{\mathrm{p}} / W_{\text {sat }}\right)\right]
$$

For the forested areas, the evaporation has been simulated with the interface model 
Table 2

Calibration parameters of the hydrological model for the 9 production zones

\begin{tabular}{lccccccc}
\hline & $\begin{array}{l}W_{\mathrm{p} \max } \\
(\mathrm{mm})\end{array}$ & $\begin{array}{c}W_{\mathrm{p} \min } \\
(\mathrm{mm})\end{array}$ & $\begin{array}{l}F_{\mathrm{n}} \\
\left(\mathrm{mm} \mathrm{day}^{-1}\right)\end{array}$ & $\begin{array}{l}C_{\mathrm{qr}} \\
\left(\text { day }^{-1}\right)\end{array}$ & $\begin{array}{l}Q_{\mathrm{rmax}} \\
(\mathrm{mm})\end{array}$ & $\begin{array}{l}C_{\mathrm{qi}} \\
\left(\text { day }^{-1}\right)\end{array}$ & $\begin{array}{l}Q_{\mathrm{imax}} \\
(\mathrm{mm})\end{array}$ \\
\hline Sandy soils & 200 & 120 & 18 & 0.3 & 100 & 0.1 & 120 \\
Recent alluvium & 240 & 40 & 10 & 0.6 & 15 & 0.1 & 50 \\
Old alluvium & 144 & 35 & 13 & 0.6 & 10 & 0.1 & 125 \\
Puddled clay & 216 & 40 & -2 & 0.6 & 40 & 0.1 & 10 \\
Fawn-coloured sand & 384 & 125 & 10 & 0.6 & 60 & 0.1 & 120 \\
Molasse, marn, clay & 384 & 90 & 6 & 0.6 & 20 & 0.05 & 90 \\
Calcereous soils & 360 & 120 & 15 & 0.6 & 40 & 0.1 & 60 \\
Marl-calcereous soils & 240 & 40 & -10 & 0.6 & 15 & 0.05 & 100 \\
Stretch of water & 20 & 20 & 1 & 0.6 & 5 & 0.1 & 5 \\
\hline
\end{tabular}

using the average vegetation parameters (leaf area index (LAI), minimum resistance to evaporation and height of trees) measured over the Landes forest (Diawara et al., 1991). The following relationship has been found:

$$
\beta=1-\exp \left(-2.5 W_{\mathrm{p}} / W_{\text {sat }}\right)
$$

The total evaporation $E_{\mathrm{s}}$ of the superficial soil layer is defined in the same way, as the sum of two terms: the bare soil evaporation and the evapotranspiration. To take into account the vertical distribution of the root system, only $20 \%$ of the total evapotranspiration can be taken up in this layer. The following relationship has been used:

$$
E_{\mathrm{s}}=0.2 f c\left(W_{\mathrm{s}} / W_{\mathrm{sat}}\right) E_{\mathrm{v}}+(1-f c) E_{\mathrm{bs}}
$$

\subsection{Introduction in the hydrological model}

These functions have been introduced in the hydrological model and the hydraulic diffusivity between the two layers of the surface, adjusted for the 9 production zones corresponding to the different soil types. The values are given in Table 2 with the other parameters of the surface scheme: maximum and minimum heights of the reservoir, $W_{\mathrm{pmax}}$ and $W_{\mathrm{pmin}}$, infiltration thresholds and rate $\left(F_{\mathrm{n}}, Q_{\text {imax }}\right.$ and $\left.C_{\mathrm{qi}}\right)$, and runoff threshold and rate $\left(Q_{\operatorname{rmax}}, C_{\mathrm{qr}}\right)$. The model has been run with this new production scheme and parameters on the 3 years between 1984 and 1986 and we analyse the results of the last 2 years (1985-1986).

\section{Calibration of the surface fluxes-surface temperature model}

\subsection{Description of the model and procedure}

The one-dimensional soil-vegetation-atmosphere model has been described in several papers (Taconet et al., 1986; Soarès et al., 1988; Sucksdorff and Ottlé, 1990; Ottlé and Vidal-Madjar 1991; BenMehrez et al., 1992a,b). The model calculates the 
surface fluxes, the surface temperature and the surface soil moisture by solving simultaneously the energy budget equation on the bare soil surface and above the canopy. An adequate partition of the incident energy fluxes between the vegetation and the soil is assumed as well as the knowledge of the daily variation of the atmospheric forcing and the characteristics of the soil and of the vegetation. The soil is represented by a two-layer system derived from Deardorff (1978) and modified by Bernard et al. (1986). The thermal and hydraulic transfers are described by three important parameters: thermal inertia, hydraulic diffusivity and limit evaporation. In the model, the vegetation is represented by one single foliage layer with negligible heat capacity, which shields the ground more or less completely depending on a shielding factor $S f$. The most sensitive parameters characterizing the canopy in the model are the vegetation height, the LAI (which corresponds to the area of leaves per unit of surface) and the minimum resistance to evaporation. All three parameters depend on the type of vegetation and its state of maturity.

The interface model can be used in the direct way to calculate the fluxes and the surface radiative temperature, if the soil and vegetation parameters, the soil humidity and the atmospheric components are given. But it can also be used inversely. Thus, if the radiative surface temperature as well as all the functional parameters are known, the model may be used to retrieve one unknown variable. Taconet et al. (1986) have shown that the knowledge of surface temperature around its maximum daily value (at midday and estimated from IR remote sensing) is sufficient to obtain one sensitive vegetation parameter of the model (in this case, the minimum resistance to the evaporation). If the six soil and vegetation parameters are known, the soil variable which can be retrieved may be the soil moisture in one of the two layers. Over bare soils, as the surface temperature is very sensitive to soil evaporation, which is mostly determined by soil humidity in the surface layer $W_{\mathrm{s}}$, the surface temperature allows to estimate $W_{\mathrm{s}}$. In the same way, over dense vegetation covers, as the evapotranspiration is strongly related to the soil humidity in the root zone, the foliage temperature permits estimation of the soil moisture of the bulk layer $W_{\mathrm{p}}$. Over partial covers, where the soil and the vegetation both contribute to the total evaporation, it is possible to estimate either of the two soil moistures $W_{\mathrm{s}}$ or $W_{\mathrm{p}}$. In our case, we have first tested the sensitivity of the hydrological model to the surface soil humidity $W_{\mathrm{s}}$, to see whether it is interesting to re-initialize it during the periods of bare soils or partial covers.

\subsection{Sensitivity tests and period of inversion chosen}

To test the sensitivity of the hydrological model to surface soil moisture, the model has been run over the 2 years $1984-1985$ with a noise of $\pm 10 \%$ added to $W_{\mathrm{s}}$. The results show that the total runoff of the year 1985 has not significantly changed. The r.m.s. difference obtained is $16 \mathrm{~mm}$, which amounts to about $3 \%$ of the total runoff. The same test has been performed to evaluate the sensitivity to the bulk layer moisture $W_{\mathrm{p}}$. In this case, for the same noise value, the changes were much greater. The r.m.s. difference was $223 \mathrm{~mm}$, which represents about $50 \%$ of the total water flows. These results are not really surprising, as the water flows are mostly determined by the 
Table 3

Coefficients used in the calculation of the thermal conductivity for the various soil types

\begin{tabular}{llll}
\hline & $\omega$ & $k_{1}$ & $k_{2}$ \\
\hline Sand & 0.31 & 0.08 & 0.93 \\
Sandy loam & 0.26 & 0.05 & 0.35 \\
Loamy clay & 0.34 & 0.06 & 0.52 \\
\hline
\end{tabular}

content of the bulk layer in our model. Moreover, the surface humidity influences the hydrologic budget only during the period of bare soils, that is, during winter months when the soils are often saturated and the evaporation is very low because of the low atmospheric demand. Then, the consequences of a poor simulation of the soil surface moisture are less important than errors on the bulk layer humidity. Consequently, it is sufficient to assimilate only the soil moisture of the bulk layer in the hydrological model. For that purpose, we have run our soil-vegetation-atmosphere interface model for all the days when cloudless satellite images are available and for all the meshes of the hydrological model.

\subsection{Calibration of the interface model}

Before the model can be run, the soil and vegetation parameters have to be adjusted for all the meshes of the hydrological model and the atmospheric input data have to be prescribed.

\section{Soil parameters}

The three key soil parameters which have to be calibrated in the model are the thermal inertia, the hydraulic diffusivity and the limit evaporation. These quantities depend on the soil moisture and on the soil characteristics. They have been adjusted locally as explained in the section 'Satellite image processing' for the three soil types available on the HAPEX square-sand, sandy loam and loamy clay (Sucksdorff and Ottlé, 1990; BenMehrez et al., 1992a). All meshes have been classified into these three classes, and the soil parameters are defined by the thermal inertia and hydraulic diffusivity, as follows.

The thermal inertia $P$ is written

$$
P=\left(\rho_{\mathrm{c}} k\right)^{1 / 2}
$$

where $\rho_{\mathrm{c}}$ is the heat capacity and $k$ is the thermal conductivity. They both vary with the soil composition and the soil moisture. According to BenMehrez et al. (1992a), we have chosen

$$
\begin{aligned}
& \rho_{\mathrm{c}}=\left(\omega+W_{\mathrm{s}}\right) 4.18 \times 10^{6}\left(\mathrm{JK}^{-1} \mathrm{~m}^{-3}\right) \\
& k=k_{1}+k_{2}\left(W_{\mathrm{s}}\right)^{1 / 2}
\end{aligned}
$$

where $\omega, k_{1}$ and $k_{2}$ are constants for each type of soil, and given in Table 3 .

The hydraulic diffusivity $D_{\mathrm{w}}$ has been calculated from Zobler's measurements 
reported by Abramapoulos et al. (1988) for sandy, loamy and clay soils and the limit evaporation fitted has already been given in the section 'Satellite image processing'.

\section{Vegetation parameters}

The three key vegetation parameters of our model are the height of the vegetation, the minimum leaf resistance to the evaporation, and the LAI. They all depend on the type and on the physiology of the vegetation.

\section{Minimum leaf resistance}

Taconet et al. (1986) and BenMehrez et al. (1992b) have shown that the minimum leaf resistance for wheat, corn and oats during the growth period has values of about $50-100 \mathrm{~s} \mathrm{~m}^{-1}$ and increases rapidly during maturity to around $1000 \mathrm{~s} \mathrm{~m}^{-1}$. As these cereals represent most of the vegetation available over the region, we have kept these values in our simulations. As the model is very sensitive to this parameter, we have tried to work on two daytime consecutive images and to obtain both soil moisture and leaf resistance. However, it has not been possible to find more than four sets of cloudless consecutive images in the 2 years of data. Therefore, we had to set the resistance of each class of vegetation assuming that, on average, all the pixels belonging to a given class have the same maturity. The chosen values have the same order of magnitude for the different classes, lower than $100 \mathrm{~s} \mathrm{~m}^{-1}$ during the growth period, varying between 100 and $500 \mathrm{~s} \mathrm{~m}^{-1}$ during the maturity period and greater than 500 and up to $1700 \mathrm{~s} \mathrm{~m}^{-1}$ after that.

\section{Leaf area index (LAI)}

This parameter has been parametrized according to Kanemasu et al. (1977), who, considering various agricultural plants, established a simple relationship between the LAI and the vegetation fractional cover $f c$ :

$$
f c=1-\exp (-0.4 \mathbf{L A I})
$$

The fractional cover is calculated with the NDVI for each mesh of the hydrological model and the LAI is estimated using Eq. (16).

\section{Height of the vegetation}

Taconet et al. (1986) have shown that this parameter is less sensitive than the other two; this is fortunate, because there is at present no way to estimate this variable from space. We had to relate it to known parameters. During the SOP of the HM experiment, the vegetation height $\left(H_{c}\right)$ and LAI have been measured and a relationship between them has been found. It can be represented by the following equations:

$$
\begin{aligned}
& H_{\mathrm{c}}=0.56 \mathrm{LAI}(\mathrm{LAI} \leqslant 1) \\
& H_{\mathrm{c}}=0.23 \mathrm{LAI}+0.33(1 \leqslant \mathrm{LAI} \leqslant 3) \\
& H_{\mathrm{c}}=0.75 \mathrm{LAI}-1.17(\mathrm{LAI} \geqslant 3)
\end{aligned}
$$

This relationship has been established for a corn crop. We could not find other relationship of this type in the literature. Therefore, as a first approximation, we 
have kept this relationship for the summer crops as this class is mostly composed of corn. However, for winter crops, as their maturity height is lower by about $1 \mathrm{~m}$ for wheat and colza, these relationships have been multiplied by the ratio of the maximum heights, that is 0.5 . For mixed crops, the ratio has been estimated as 0.7 . In this way, we have

$$
\begin{aligned}
& H_{\mathrm{s}}=H_{\mathrm{c}} \\
& H_{\mathrm{w}}=0.5 H_{\mathrm{c}} \\
& H_{\mathrm{m}}=0.7 H_{\mathrm{c}}
\end{aligned}
$$

where $H_{\mathrm{s}}$ is the height of summer crops, $H_{\mathrm{w}}$ the height of winter crops and $H_{\mathrm{m}}$ the height of mixed crops. It is clear that for this study that we are a little short of measurements to calibrate accurately all parameters of our model. However, we will see below that despite the calibration uncertainties, the model is able to simulate correctly the hydrologic budget and its variation. We can note that, in the future, it will be possible to estimate all these parameters from space. The synergistic use of optical instruments and microwave radar might permit us to obtain the surface temperature from the thermal IR measurements, the amount of vegetation from the NDVI, its height with synthetic aperture radar (SAR) interferometry and finally the soil roughness from the SAR back-scattering coefficient, directly related over bare surfaces to its superficial moisture. This is possible today, by combining the instruments of the European satellite ERS1 and the US NOAA series.

\section{Atmospheric data}

The input atmospheric data necessary to run the interface model are the daily variations of the incoming solar radiation, the air temperature and humidity, and the wind speed at $2 \mathrm{~m}$. All these measurements were made automatically every $30 \mathrm{~min}$ at the PATAC weather stations during the 2 years of the experiment. These stations are distributed all over SW France. A first analysis of the data for the days corresponding to the satellite data acquired, has shown the great homogeneity of the air temperature data, with a small negative gradient from the SW to the NE of the square (around $1 \mathrm{~K}$ ). The air humidity and the wind speed is more variable. To assign these four variables to each of the $5 \mathrm{~km} \times 5 \mathrm{~km}$ meshes, as a first approximation, we have interpolated the data at the centre of each mesh by a linear interpolation in terms of the different distances to the stations. These data have been interpolated on a time step of 6 min to run our interface model.

\section{The inversion procedure}

Once the model is calibrated and the atmospheric data are prepared, the model can be run on all the meshes of the hydrological model. However, as we want to use it in the inverse way, we have to extract the average surface temperature for each mesh from the thermal IR data.

The estimation of land surface temperature from thermal IR remote sensing is 
difficult because the radiation emitted from the surface and measured by the satellite depends both on its temperature and on its emissivity. As there is no way at the present time to estimate the emissivity from space and as it can be much less than unity over bare soils, it is not easy to estimate the confidence that one can have in its estimation. In this study, as we have worked over vegetative areas, we can assume that the emissivity is around 0.98 with a standard deviation of 0.01 , which leads to an error less than $1.5 \mathrm{~K}$ on the estimated temperature (Ottlé and Stoll, 1993).

\subsection{Atmospheric corrections}

To estimate the surface temperature from the thermal IR satellite measurements, the radiances or the brightness temperatures must first be corrected for atmospheric absorption. This can be done by different methods, and a recent study (Ottle and Vidal-Madjar, 1992) has shown that both give approximately the same results with an r.m.s. difference less than $1 \mathrm{~K}$. We have used the so-called split-window method (Prabhakara et al., 1974; Anding and Kauth, 1979; Deschamps and Phulpin, 1980) to calculate the surface temperature. This method uses the differential absorption in the two spectral bands of channels 4 and 5 of AVHRR (11 and $12 \mu \mathrm{m})$ to eliminate the atmospheric effects. The surface temperature may be written in terms of the two brightness temperatures $T_{4}$ and $T_{5}$ measured in the two spectral bands and is given by

$$
T_{\mathrm{s}}=a_{1} T_{4}+a_{2} T_{5}+a_{3}
$$

where $a_{1}, a_{2}$ and $a_{3}$ have been calculated by regression between surface temperature and associated brightness temperatures modelled by means of an accurate radiative line-by-line transfer model for a large number of atmospheric situations, for different surface emissivity values and viewing conditions (Ottle and Vidal-Madjar, 1992). The coefficients chosen are those calculated for temperate atmospheres and for a surface emissivity of 0.98 . They depend on the satellite viewing angle which has been calculated for each image. The surface temperature has been calculated on a pixel-bypixel basis and averaged over the $5 \mathrm{~km} \times 5 \mathrm{~km}$ meshes.

\section{Inversion of the interface model and assimilation of the inferred soil moisture in the hydrological model}

The objective of our study is to use the estimation of the soil moisture deduced from the energy budget observed from space, to correct the simulated content of the hydrological model's surface reservoir. For that purpose, we have kept only the images corresponding to partial covers with an LAI greater than two, where we have tested that the radiative surface temperature is more sensitive to root zone humidity than to superficial humidity.

For each of the days for which all data and satellite images are available, the interface model can be run with the hydrological model surface moisture as an initial value on all the meshes. The soil humidity $W_{\mathrm{p}}$ is modified until the difference between 
Table 4

Annual water flows simulated by the three versions of the model

\begin{tabular}{llc}
\hline & \multicolumn{2}{l}{ Water flow $\left(\mathrm{mm} \mathrm{year}^{-1}\right)$} \\
\cline { 2 - 3 } & 1985 & 1986 \\
\hline Model 1 & 448 & 383 \\
Model 2 & 479 & 398 \\
Model 3 & 480 & 408 \\
\hline
\end{tabular}

the modelled surface radiative temperature and the observed one is less than $1.5 \mathrm{~K}$. If the variation of the soil moisture has no effect on the surface simulated temperature, the model is not inverted.

The difference between the soil moisture inferred in this way and the initial one simulated by the hydrological model is then averaged on all meshes constituting the precipitation areas presented in Section 3.1. We have proceeded in this way because the calculations in the hydrological model are made by precipitation and production zones. The difference is finally introduced in the hydrological model and it is run until a new satellite image is available. This work has been done for 24 images on the 2 years of the experiment.

\section{Results}

\subsection{Annual water flows}

In this section, we will compare three simulations of the hydrological model on the 2 years 1985-1986: the first, Run 1, was run with the first version of the hydrological model (Model 1; Girard and Boukerma's surface parametrization), the second, Run 2 , was run with the second version of the model (Model 2) in which the calculation of the surface budget has been changed as well as the calculation of the evaporation, and the last, Run 3, is the second version of the model (Model 2) in which we have assimilated the soil moisture inferred from the thermal IR imagery.

The results on the total runoff are shown for the 2 years and the three versions of the model in Table 4. The total runoff over the ten river basins has increased by $33 \mathrm{~mm}$ in 1985 and by $15 \mathrm{~mm}$ in 1986 between Run 2 and Run 1 . The differences are less important when comparing Run 3 and Run 2, where the difference is $1 \mathrm{~mm}$ in 1985 and $11 \mathrm{~mm}$ in 1986. This increase of the total runoff with the new surface scheme is mostly owing to the evapotranspiration calculation. A monthly analysis shows that the evaporation is lower with the new scheme during the periods of partial cover, so the reservoirs empty more slowly. The consequence is that the evapotranspiration is greater during summers. These modifications lead to larger annual water flows. Comparing Runs 3 and 2, we can see that the assimilation tends in general to increase the content of the surface reservoir and to increase the evaporation during the vegetative period as well as the water flows. 

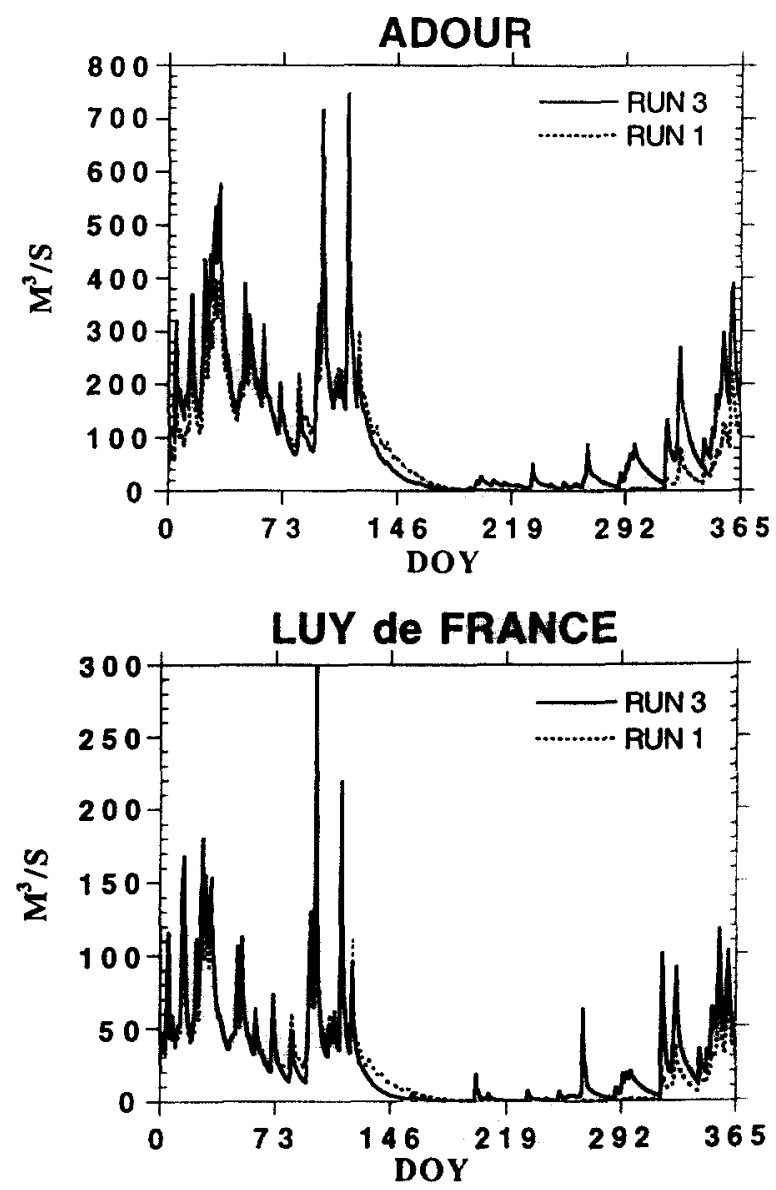

Fig. 7. Daily water flows modelled over the Adour and Luy de France river basins.

\subsection{Daily water flows}

To appreciate the improvements that result from the use of this new scheme and the assimilation of soil moisture, the water flows calculated at the outlets of the ten river basins of the area under study have been plotted. We show in Fig. 7 the two river basins of the southern part of the HM square: the Adour river basin and the Luy de France river basin. The first covers an area of $6925 \mathrm{~km}^{2}$ and the second an area of $1184 \mathrm{~km}^{2}$. The water flows are plotted for the year 1986 .

The comparison shows that the simulated flows are very similar in both runs. The flood peaks are a little larger and the recession is quicker in Run 3 than in Run 1. However, the major difference is that the small floods after the summer at the precipitation recovery are simulated on Run 3, whereas they did not appear in Run 1. There are two reasons for this: the second surface scheme consists of two layers and the calculation of the evaporation limits the drying of the soils. Consequently, the 


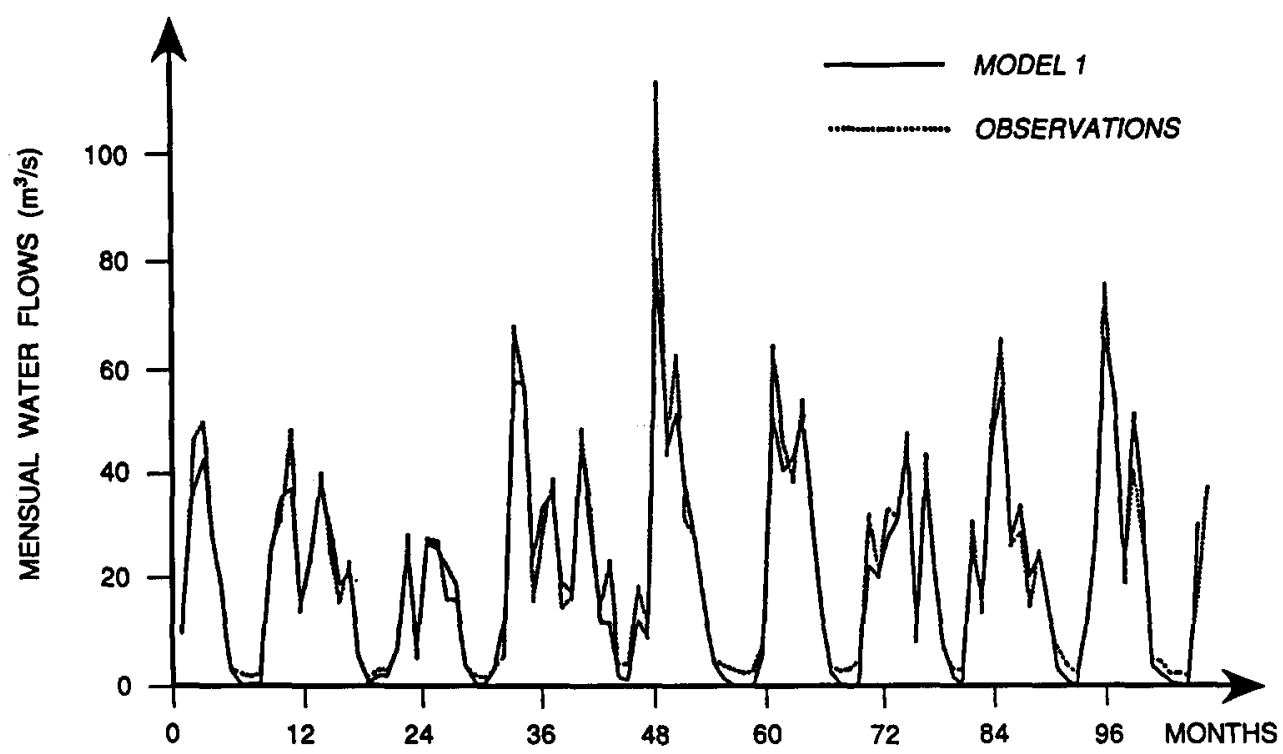

Fig. 8. Monthly water flows over the Luy de France river basin obtained by Model 1 compared with the observations.

response to the precipitation is quicker compared with a model with only one layer which is generally completely empty at the end of summer. Unfortunately, we do not have the measured flows for these 2 years, but looking at the results of Model 1 for the years 1974-1982 and for the Luy de France river basin, in Fig. 8 we see that the periods of low flows (summer months) and peak flows are generally underestimated. As far as daily water flows are concerned, the same drawback is observed for the Adour river basin (Fig. 9): the flood peaks are underestimated, the recession is too slow and the low water discharge is too high compared with the observations. It seems that these drawbacks are corrected with the new surface scheme.

\subsection{Soil moisture}

It is interesting to compare now the evolution of the surface reservoir $W_{\mathrm{p}}$ during the 2 years studied, for the three runs (Fig. 10), for different meshes corresponding to SAMER stations, where neutron probe measurements have been taken in the first $1 \mathrm{~m}$ of soil. This comparison has been made for all SAMER stations, but we show here the results for two sites, Vicq and Bats, corresponding respectively to SAMER 7 and SAMER 8 in Fig. 3. It is difficult to compare local measurements with the changes in the average soil moisture over a mesh of $5 \mathrm{~km} \times 5 \mathrm{~km}$ but it allows us to see if the annual evolution is correct. A preliminary study has shown that after elimination of the irrigated stations, the data are very homogeneous and the soundings can be 


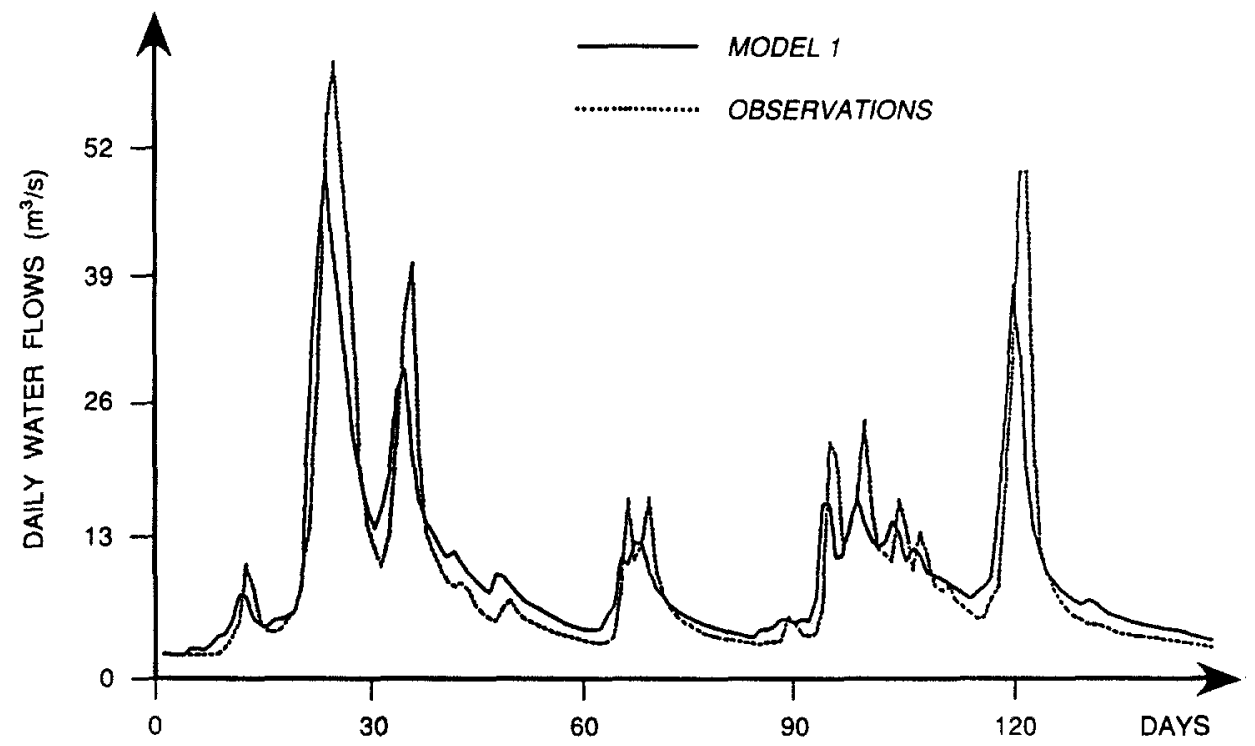

Fig. 9. Daily water flows over the Adour river basin obtained by Model 1 compared with the observations.

separated in two classes corresponding to the soil type-sandy or loamy soils. This result has also been shown by Goutorbe et al. (1989).

Comparing Run 2 with Run 1, we see that the water budget seems to be better represented with the new scheme. The drying of the surface begins later and is slower, and the remoistening is quicker and in better agreement with the observations. The maximum drying out has also the right order of magnitude and we no longer observe cases where the minimum level of the reservoir is reached at the beginning of summer and evaporation is zero in the absence of precipitation.

In the same figure (Fig. 10), Run 3 simulation is also plotted. The assimilation days are noted on the horizontal axis and in this case no conclusion can be drawn; for some stations, the data assimilated tend to bring the simulation closer to observations and in other cases, it is the contrary. Overall, however, it seems that the soil moisture is better simulated in Run 3.

\subsection{Evaporation}

An important point is the estimation of evaporation. The SAMER stations give an estimate of evaporation at the field scale which is representative of a larger region. Andre et al. (1990) have shown that the SAMER measurements are well correlated with the aircraft flux measurements integrated over a larger region.

We have compared evaporation as measured by the SAMER stations during the 5 months of measurements of the SOP in 1986 with the simulated evaporation over the corresponding meshes (Fig. 11). The results show a better agreement of Run 3 with the observations, especially for the months of July and August when Run 1 simulates very low and unrealistic values, a consequence of the drawback indicated above 

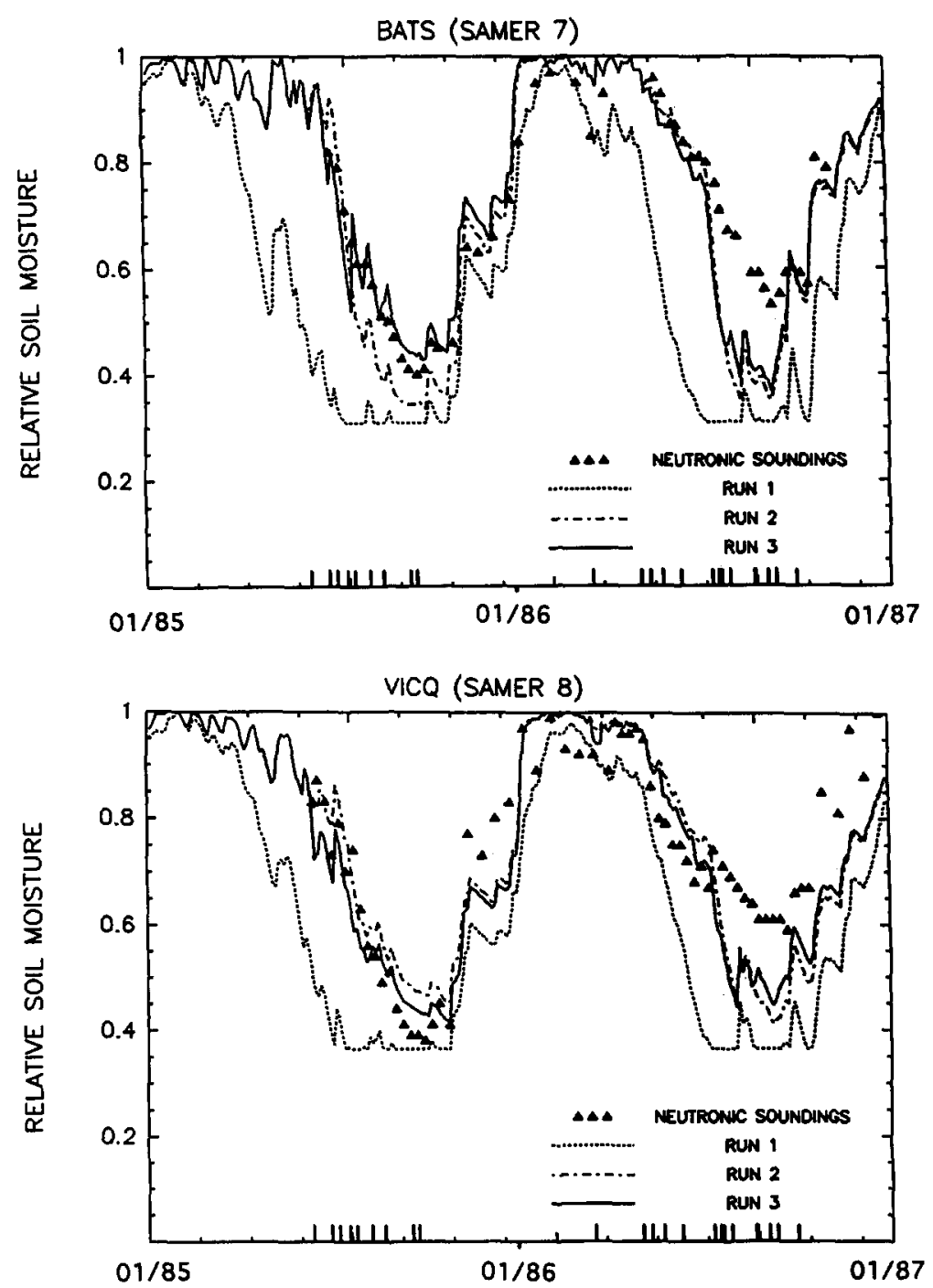

Fig. 10. Modelled soil moisture compared with the observations for two SAMER sites.

(excessive evaporation as long as there is some water in the soil and nothing more until the reservoir fills up again). The standard deviation is 1.1 for Run 1 against SAMER measurements and 0.7 for Run 3 .

\section{Conclusion}

The parametrization of the surface exchanges at the soil-atmosphere interface is a domain which has been often neglected in hydrological models. This study shows the 

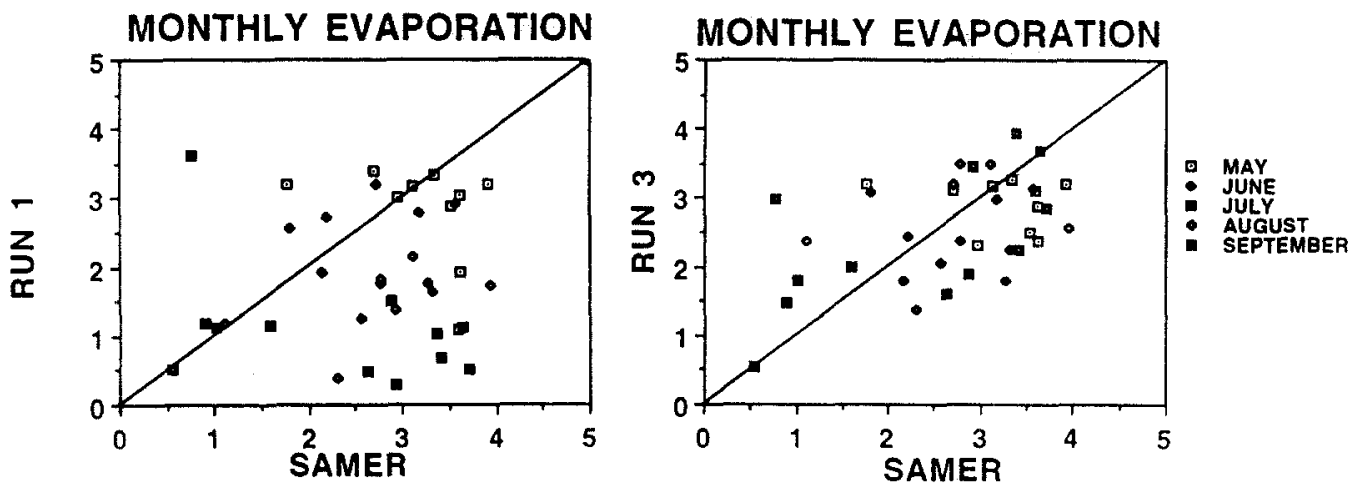

Fig. 11. Monthly evaporation simulated by Runs 1 and 3 compared with the SAMER measurements.

improvements that result from the consideration of a realistic and physically based modelling of the superficial soil. The use of a two-layer parametrization of the surface and the taking into account of the vegetation and of its evolution contribute to large improvements in the daily simulation of soil moisture and of the water flows. We have seen also that the regional evaporation calculated by the hydrological model is more realistic and in better agreement with the observations. In this study, we had to use the soil representation of Bernard et al. (1986) for consistency with our soil-atmosphere interface model. It is obvious that a two-layer model performs better than a singlelayer one because it reacts more quickly to rainfall. However, this parametrization might be improved in various ways. For example, it would be interesting to test more sophisticated multi-layer modellings. The interception of precipitation by the vegetation is also a process which should be taken into account and investigated. Our results also present a method to correct the hydrological model's simulation of the surface water exchanges by using an indirect measurement of the soil's capability to evaporate moisture. This estimation from space of the soil relative humidity permits us not only to palliate the derivations of the models owing to the imperfect parametrizations of the different processes, but also to correct, to some extent, the errors made in the estimation of the water supplies of the hydrological systems related to the imprecise knowledge of the spatial variation of the precipitation and the failure to take into account irrigation, which cannot be neglected in most agricultural regions.

This work is a first attempt to use visible and thermal IR remote sensing in hydrological models. The classification of vegetation and the following of its seasonal evolution can be easily implemented. Clearly, the inversion of the interface model on the grid meshes and the assimilation of the soil moisture into the hydrological model is a difficult task and requires a meteorological network for the interface model to be run. However, we have shown that if the atmospheric forcing and the soil and vegetation types are known, all the parameters can be estimated either from literature measurements or from remote sensing data. As the mesh size of the hydrological model is at least of the order of $1 \mathrm{~km}^{2}$, remote sensing tools are well adapted for the estimation of some surface parameters of the hydrological models. Another 
domain which should help improve hydrological modelling is the estimation of precipitation. Combining the future precipitation spaceborne radars with the IR sensors will provide information on the spatial variability of rain and on its characteristics. In conclusion, different techniques will permit, in the very near future, the estimation of important hydrological variables from space. Investigations are necessary now to find ways to introduce this information easily into hydrological models.

\section{Acknowledgements}

The authors would like to thank especially G. Girard for supplying the hydrological model and for his useful advice. We thank $M$. BenMehrez for numerous fruitful discussions, and also all our colleagues from CRPE, METEO FRANCE and INRA who provided us with the field data, the PATAC and SAMER measurements and the NOAA-AVHRR data. Thanks are also due to C. Tiffon and A. Derode for their help in the image processing. This study was supported by the Centre National d'Études Spatiales and the Centre National de la Recherche Scientifique.

\section{References}

Abramapoulos, F., Rosenzweig, C. and Choudhury, B., 1988. Improved ground hydrology calculations for global climate models (GCM): soil water movement and evapotranspiration. J. Clim. Appl. Meteorol., 1: 921-941.

Anding, D. and Kauth, R., 1979. Estimation of sea surface temperature from space. Remote Sensing Environ., 1: 217-220.

André, J.C., Bougeault, P. and Goutorbe, J.P., 1990. Regional estimates of heat and evaporation fluxes over non-homogeneous terrain. Examples from the HAPEX-MOBILHY program. Boundary-Layer Meteorol., 50: 77-108.

André, J.C. et al., 1988. HAPEX-MOBILHY: first results from the Special Observing Period. Ann. Geophys., 6: 477-492.

BenMehrez, M., Taconet, O., Vidal-Madjar, D. and Sucksdorff, Y., 1992a. Calibration of a fluxes model over bare soils during HAPEX-MOBILHY experiment. Agric. For. Meteorol., 58: 257-283.

BenMehrez, M., Taconet, O., Vidal-Madjar, D. and Valencogne, C., 1992b. Estimation of canopy stomatal resistance and canopy evaporation during HAPEX-MOBILHY experiment. Agric. For. Meteorol., 58: 285-313.

Bernard, R., Soarés, J.V. and Vidal-Madjar, D., 1986. Differential bare field drainage properties from airborne microwave observation. Water Resour. Res., 22(6): 869-875.

Carlson, T.N., Dodd, J.K., Benjamin, S.G. and Cooper, J.N., 1981. Satellite estimation of the surface energy balance, moisture availability and thermal inertia. J. Appl. Meteorol, 20: 67-87.

Deardorff, J.W., 1977. A parametrization of ground surface moisture content for use in atmospheric prediction models. J. Appl. Meteorol., 16: 1182-1185.

Deardorff, J.W., 1978. Efficient prediction of ground surface temperature and moisture, with inclusion of layer of vegetation. J. Geophys. Res., 83(C4): 1889-1903.

Deering, D.W., Rouse, J.W., Haas, R.H. and Schall, J.A., 1975. Measuring forage production of grazing units from Landsat MSS data. Proceedings of the 10th International Symposium on Remote Sensing of the Environment, Ann Arbor, MI, p. 1169.

Deschamps, P.Y. and Phulpin, T., 1980. Atmospheric correction of infrared measurements of sea surface temperature using channels at 3.7, 11 and $12 \mu \mathrm{m}$. Boundary Layer Meteorol., 18: 131-143.

Diawara, A., Lousteau, D. and Berbigier, P., 1991. Comparison of two methods for estimating the 
evaporation of a Pinus pinaster stand: sap flow and energy balance with sensible heat measurements by a fluctuation method. Agric. For. Meteorol., 54: 49-66.

Girard, G., 1974. Modèle global ORSTOM. Première application du modèle journalier à discretisation spatiale sur le bassin versant de la crique Grégoire en Guyane. In: Atelier hydrologique sur les modèles mathématiques. ORSTOM, Paris.

Girard, G. and Boukerma, B., 1985. Projet HAPEX-MOBILHY, Calage du Modèle Hydrologique. Rapport LHM/RD/85/110, CIG, Fontainebleau.

Goutorbe, J.P., Noilhan, J., Valencogne, C. and Cuenca, R.H., 1989. Soil moisture variations during HAPEX-MOBILHY. Ann. Geophys., 7(4): 415-426.

Holben, B.N., 1986. Characteristics of maximum-value composite images from temporal AVHRR data. Int. J. Remote Sensing, 7(11): 1417-1434.

Itier, B., 1982: Révision d'une methode simplifiée pour la mesure du flux de chaleur sensible. J. Rech. Atmos., 16: 85-90.

Kanemasu, T., Rosenthal, U.D., Raney, R.J. and Stone, L.R., 1977. Evaluation of an evapotranspiration model for corn. Agron. J., 69: 461-464.

Kustas, W.P., Jackson, R.D. and Asrar, G., 1989. Estimating surface energy balance components from remotely sensed data. In: G. Asrar (Editor), Theory and Applications of Optical Remote Sensing. Wiley, New York, pp. 604-627.

Ledoux, E., 1980. Modélisation intégrée des écoulements de surface et des écoulements souterrains sur un bassin hydrologique. Thèse de Docteur-Ingénieur, ENSMP et Université P.M. Curie, Paris.

Ottlé C. and Stoll, M., 1993. Effect of atmospheric absorption and surface emissivity on the determination of land surface temperature from infrared satellite data. Int. J. Remote Sensing, 14(10): 2025 2037.

Ottlé, C. and Vidal-Madjar, D., 1991. Introduction of a realistic soil-vegetation component in a hydrological model: application to HAPEX-MOBILHY experiment. In: T.J. Schmugge and J.C. André (Editors), Land Surface Evaporation. Springer, Berlin, pp. 137-143.

Ottlé C. and Vidal-Madjar, D., 1992. Estimation of land surface temperature with NOAA9 data. Remote Sensing Environ., 40(1): 27-41.

Ottlé, C., Sucksdorff, Y., and BenMehrez, M., 1991. Use of thermal infrared remote sensing for water budget studies. Adv. Space Res., 11(3): 163-167.

Ottlé, C., Vidal-Madjar, D. and Girard, G., 1989. Remote sensing applications to hydrological modelling. J. Hydrol., 105: 369-384.

Phulpin, T., Jullien, J.P. and Lasselin, D., 1989. AVHRR data processing to study the surface canopies in temperate regions. First results of HAPEX-MOBILHY. Int. J. Remote Sensing, 10 (4-5): 869-884.

Prabhakara, C., Dalu, G. and Kunde, V.G., 1974. Estimation of sea surface temperature from remote sensing in the $11-13 \mu \mathrm{m}$ window region. J. Geophys. Res., 79: 5039-5044.

Riou, C, 1982. Une expression analytique du flux de chaleur sensible en conditions suradiabatiques à partir de mesures du vent et de la température à deux niveaux. J. Rech. Atmos., 16: 15-22.

SMIRSO, PATAC, 1985. Rapport sur l'état d'avancement du projet au 31 Mai 85. Rapport interne du SMIRSO, Mérignac, France.

Soarés, J.V., Bernard, R., Taconet, O., Vidal-Madjar, D. and Weill, A., 1988. Estimation of bare soil evaporation from airborne measurements. J. Hydrol., 99: 281-296.

Sucksdorff, Y. and Ottlé, C., 1990. Application of satellite remote sensing to estimate areal evapotranspiration over a watershed. J. Hydrol,, 121: 321-333.

Taconet, O., Bernard, R. and Vidal-Madjar, D., 1986. Evapotranspiration over an agricultural region using a surface flux/temperature model based on NOAA-AVHRR data. J. Clim. Appl. Meteorol., 25: 284307.

Tanré, D., Deroo, C., Duhaut, P., Herman, M., Morcrette, J.J., Perbos, J. and Deschamps, P.Y., 1990. Description of a computer code to simulate the satellite signal in the solar spectrum: the $5 \mathrm{~S}$ code. Int. $J$. Remote Sensing, 11: 659-668.

Wetzel, P.J. and Chang, J.T., 1987. Concerning the relationship between evapotranspiration and soil moisture. J. Clim. Appl. Meteorol., 26: 18-27. 